\title{
UC-NRLF
}

\section{B 4285772}

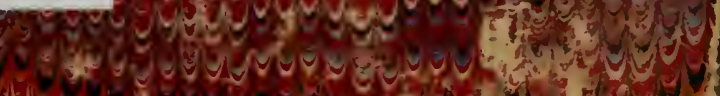
YVy

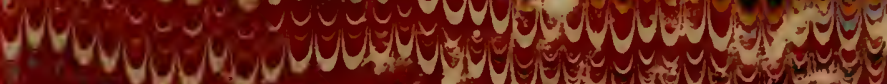

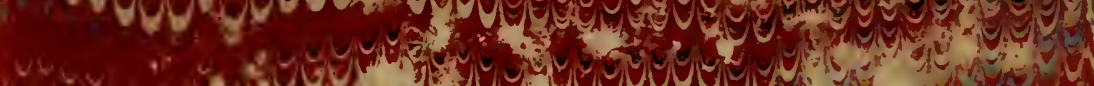

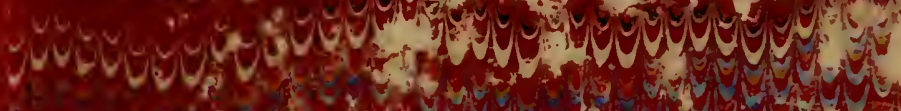
$40 \mathrm{~N}$

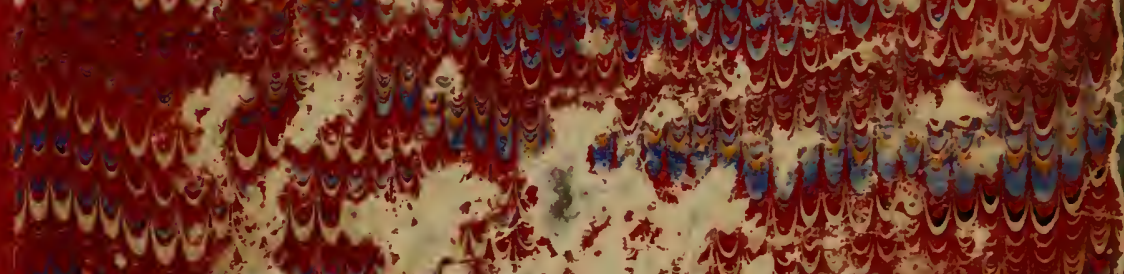

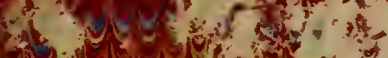

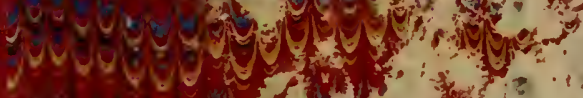
900 g.

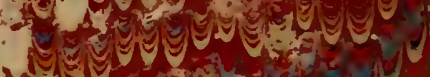

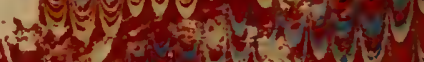

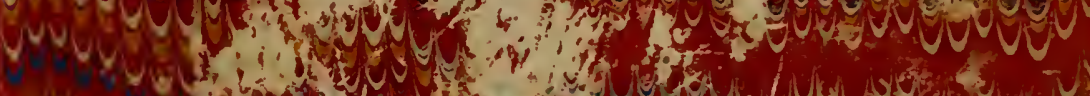
179 de

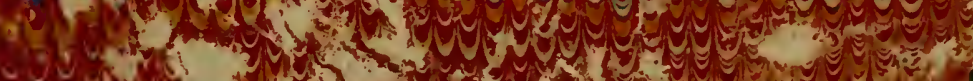

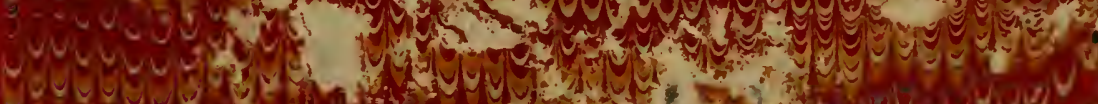

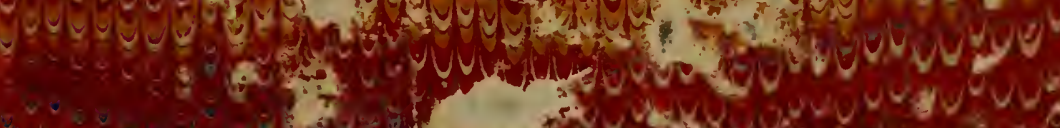

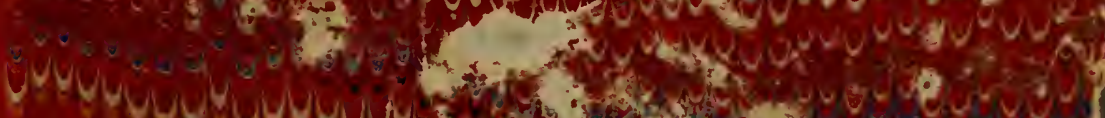

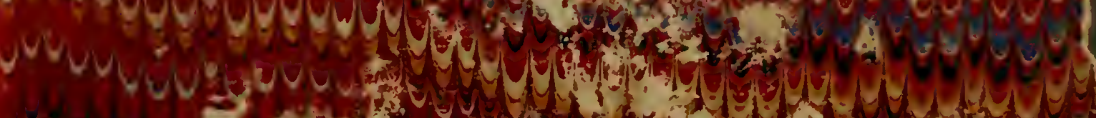
- Exam a

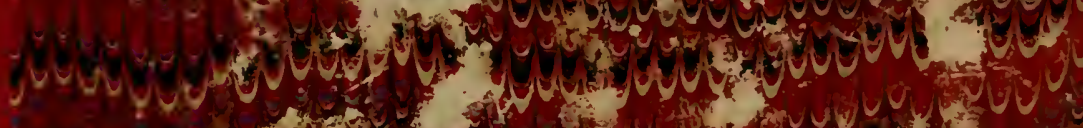

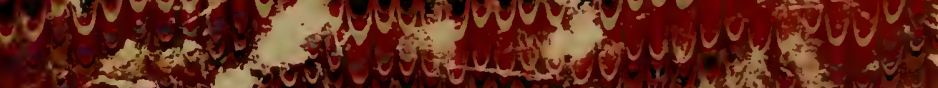

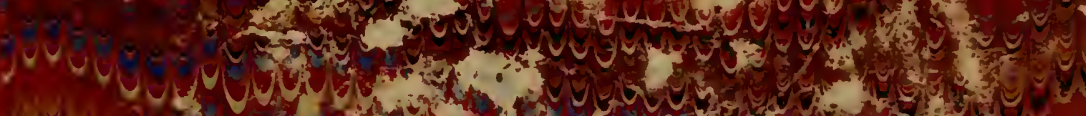

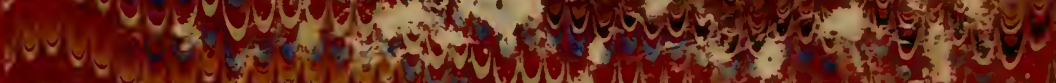

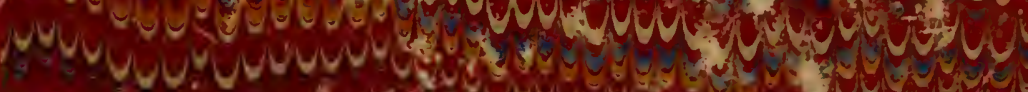

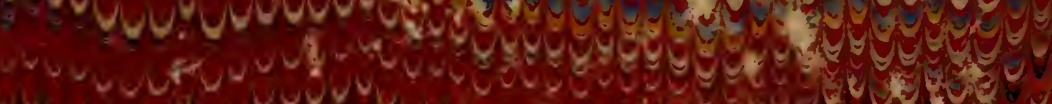

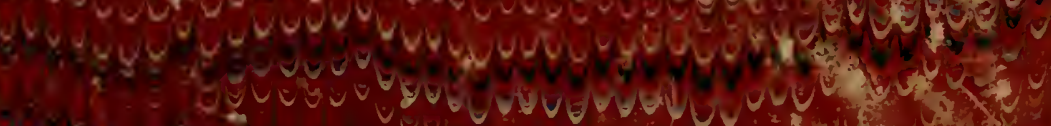

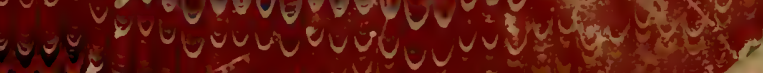




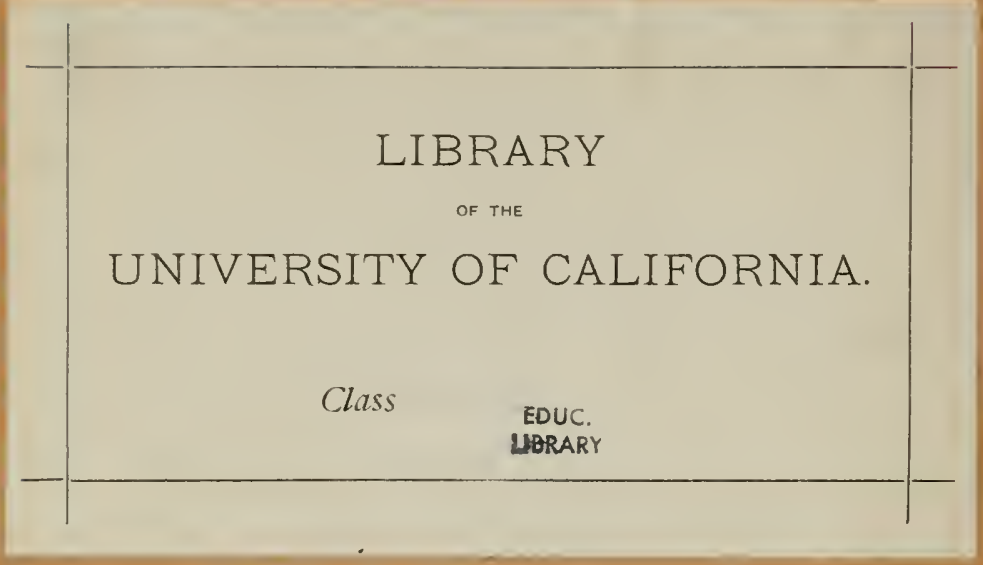





\title{
THE RELATION OF GEOGRAPHY TO THE SCIENCES.
}

\author{
By HERBERT M. WILSON, \\ United States Geological Survey.
}

WE are passing through a period in which methods of business, of education, and of government are rapidly developing. From the centralization of many diverse units under one administration, as in the change from the college to the university, from the company to the syndicate, from the kingdom to the empire, there results a broadening of interests. But this very aggregation of interests and power gives opportunity for, and demands, more detailed study and more careful management of the component parts. The small college, at which only a few general branches of learning were taught, is giving place to the greater university, in which all branches of learning are represented and yet the minutest detail is taught in each specialty. The individual owner of the blast furnace or steel-rail mill is being replaced by the great syndicate, which mines the fuel and the ore, transports them to the mill, and works the product of the latter into finished commercial form; yet the very magnitude of the syndicate's interests results in the more scientific development of its resources and products through the medium of trained specialists, who supervise the details of every branch of its industries.

This spirit of the times is expressing itself in discussions by our educators concerning the place of geography among other sciences. That the reaction on geography of the study of other branches of science has led to discussion of this subject is good cause for congratulation.

Some regard geography as scarcely a composite science, but only a mosaic of others, having little right to a place among such specialized sciences as geology, astronomy, botany, ethnology, etc., from each of which it borrows something. Others conceive it to be one of the general or administrative sciences, correlating the truths of the more detailed sciences and knitting their results into a harmonious whole.

It will be well, in the beginning, to recall the derivation of the name and to observe the danger of a too literal translation. "Geography" has generally been held to be a "description of the earth," and as 
such even the first of great modern geographers, Alexander von Humboldt, considered it. He was probably the first to point out that the different special natural sciences needed to be supplemented by a generalizing science which should bring together the isolated results of the others and trace from them the general features of the world. He said that the results of scientific research should be considered in their vast relations to mankind, and showed that geography does this. More recently Karl Ritter, another of the founders of the modern German school of geography, has adopted as a liberal translation of "geography" the word Erdkunde, which may be defined as "knowledge of the earth." By this he means that geography is not so much a mere description as a subject full of scientific problems requiring solution.

Lieutenant-General R. Strachey, one of the pioneer Englishmen in modern geographic methods, has said: "I therefore claim for geography, in the sense that I have spoken of it, a place among the natural sciences, as supplying the needful medium through which to obtain a connected and consistent conception of the earth and what is on it, on the importance of which I have already insisted. In this respect the position of geography may be looked on as analogous to that of mathematics." Another Englishman, Professor H. F. Tozer, who is primarily a student of the historical side of geography, claims that geography "is the most central in its position of all the sciences, standing as it does half-way between history, sociology, and the other studies which relate to man, on the one side, and those which deal with the composition of the earth, which is his dwelling-place, such as geology, on the other; so the history of geography, especially that of its earlier stages, when these cognate subjects were still in their infancy, is fruitful in information relating to them:" Still another English geographer, Professor E. C. K. Gonner, in considering commercial geography, describes geography as "a study of the environments of man." He holds that its function is to observe, arrange, and describe the physical conditions under which man livese, and to indicate the part which these conditions play in determining the course of his development and the nature of his occupation.

Finally, reference might be made to the writings of Powell, Richthofen, and Davis, among the more prominent of the modern school of so-called physical geographers, in which may be found conceptions of geography in its special relation to geologiy and meteorology; or to the writings of Réclus, who emphasizes the ethnologic side of 
geography, and of Freeman, who has shown it to be the most important factor in the history of nations.

The student will thus discover that geography is not merely a patchwork of other sciences, but that, as a rule, each geographer is a specialist, who, while indicating the relations of his favorite specialty to the other sciences, magnifies his own, be it geology as with Suess, ethnology as with Réclus, political geography as with Ratzel, historical geography as with Tozer, or commercial geography as with Gonner.

So it has ever been with each of the more restricted sciences. Not so very long ago geologists based their lore on biology, and palæontology was the keystone of their theories and their measure of time. They then took up the dynamics of geology and founded their pet theories on vulcanism. Now they have become geomorphologists, and the surface or physiographic forms, as produced chiefly by erosive action, are the key by which they unlock hidden mysteries. The lithologic composition of the rocks, revealed by the microscope, furnishes their basis of classification and measure of time. Hence the modern school of geologists, recognizing the geographic (topographic) side of their science, are trenching so closely on the domain of what they conceive to be geography that many of them have come to believe, as do some historians, meteorologists, and ethnologists, that the science of geography has ceased to exist.

This brings us to a realization of how imperfectly the true meaning of the term "geography" is as yet understood, not only in our own country, but even in Germany, the most advanced of all countries in geographic teaching. It is the geologists whom we must gratefully credit with having forced the issue, through mistaking one of the components of geography, namely topography, for the whole, and thus limiting the science to its orographic phase. This is clearly shown in the statement made before this association last year by Professor W. H. Norton, who aptly characterized the new geologic cult, geomorphology, as "the child of geology and geography," and who properly decided that "the overlap land of geomorphology may be claimed by geology with as sure a right as any of its other provinces, such as palæontology." If we substitute here for "geography" the name intended, "topography," and also in his question, "Should land forms be taught in high schools chiefly as physical geography or as geology?" substitute for "physical geography" "topography," we arrive at a true conception of the difficulties raised by topographic geologists, if I 
may so characterize them. It is worthy of note that Professor Norton says of this predominant influence in present-day so-called geographic thought that the "professors of physical geography belong, notwithstanding, to the brotherhood of the hammer." It is but natural that the leader in this school, Professor W. M. Davis, should, in his admirable treatise on land forms, unconsciously realize the narrowness of the physical side of geography alone by pointing out the application of the science to the life of plants and animals and of man, thus placing himself among the first of his cult to appreciate that geography is sornething more than geomorphology.

The true place of geography has now been indicated, though few geographers have been or will be sor.comprehensive of grasp and so broad in culture as to compass the whole subject and favor no specialty. Dr. Wm. T. Harris, United States commissioner of education, best indicated the full scope of geography as a science when he wrote: "Geography unites the study of the natural elements, land and water, climate and productions, with the study of man's present conquest and use of the same." Professor Tozer, in the statement previously quoted, characterized geography in similar terms. The Committee of Fifteen also indicated in their report the important position of geography among the sciences when they referred to it as one of the most important of all branches taught in the common schools, "a composite science or conglomerate of several sciences united with several arts." This last phrase clearly indicates that geography is an intermediary science-that its true functions are to correlate the sciences - physical, natural, commercial, historical, and mathematical with the arts. It is indeed true that one of the interests in the manysided science of geography is lost if the student limits his investigations to the surface of the earth and its envelopes of air and water, and fails to consider the human side - the relation of man to his habitat, and its reaction upon him, as shown in the social and political history of the race. As Humboldt has expressed it, "the unity of a physical description of the world is no other than that found also in the study of history." Both are exact sciences, dealing not in doubtful premises nor dependent on unproved theories, but founded on facts empirically determined.

As recently pointed out by Dr. Martha Krug Genthe, "the geography of plants or animals is, then, as different from descriptive botany and zoölogy as the geological knowledge of the earth is from 
mineralogy." Hence the physical description of the world by a geographer of Humboldt's type is "not to be confounded with a so-called cyclopædia of natural sciences." In such geographic writings details are studied only in their relation to the whole as parts of the world's phenomena. In refutation of the charge that geography is but "an agglomeration of fragmentary knowledge borrowed from a dozen other sciences," the same writer has well shown that there is "no science now known in which one mind can have an equally complete command of all subdivisions; even the greatest men in medicine, zoölogy, history, etc., are specialists in some definitely limited areas." Hence a physician is still a scientist, though he be not a specialist in laryngology or gynæcology; and a place in science is granted to the geologist, though he be not a palæontologist.

Perhaps the relation which geography bears to kindred sciences may be best likened to that borne in these days of specialization by civil engineering to allied branches of the engineering profession. The assertion is frequently made that the parent profession, civil engineering, has ceased to exist; that it is but a hash of its component specialties-hydraulic, sanitary, topographic, railroad, bridge, mining, electrical, and mechanical engineering - from each of which it borrows a little. The absurdity of this becomes evident when we consider that the electrical engineer who builds a rural trolley line or develops electric energy from water power, and the mining engineer who drives a tunnel or constructs a tramroad, may with equal truth be said to be practicing a composite calling composed of civil, hydraulic, and mechanical engineering. In this day of specialization and of administrative concentration, it is but natural that the foremost workers in scientific as in commercial pursuits, jostled by the elbows of the devotees of sister-sciences, should give expression to their "community of interests" feeling by endeavoring to absorb or attach all that comes in touch with them. Civil engineering still remains the parent or administrative engineering profession, which correlates the wisdom of its component branches by utilizing on the greatest works the services of their specialists. Yet, in the beginning, the greatest of our civil engineers were themselves specialists, and they may still be called upon to lend their special services to mining, hydraulic, and electrical engineers, or to architects.

It is so with geography, the oldest of sciences, which properly bears the same relation to the natural sciences that civil engineering 
holds to the allied engineering professions, or that the president of a syndicate holds to one of its component, yet semi-independent, corporations. It is an administrative or correlating department, yet at times lending its knowledge of the specialty from which it springs to the development of kindred branches in the world's work.

And this brings us to another division of the subject - the place of geography in education - which, it seems, must be considered in this discussion. The teaching of geography in the more advanced grades should be so planned as to direct observation to the various natural features and physical phenomena, and to the reaction of this environment on man and his occupations. It should also give attention to the recording of such features in the form of concise and systematic reports. The civil or mining engineer, lawyer, historian, promoter of financial and commercial undertakings, geologist, ethnologist, biologist, meteorologist, and persons engaged in kindred professional occupations, are constantly called upon to conduct investigations and to submit reports which require a preliminary description of the natural features and the arts of the region under consideration.

An examination of the great government survey reports, the works of historians, or the projects of civil engineers will disclose the value of higher geographic training. A large proportion of our civil and mining engineers have, at some period in their careers, had to investigate and report upon projects in localities little known. The writer is one of hundreds who have made preliminary surveys for railways, irrigation projects, or plans for river and harbor improvement, or for the development of mineral resources in Mexico, China, British America, portions of our far West, or in better-known and better-developed parts of the earth. Their reports to the stockholders of the companies or other employers, if consisting only of a brief statement of the engineering problems immediately involved, furnish few of the data necessary to enable the projectors of such enterprises to determine the financial possibilities or to estimate the resources of the region. But such reports convey an entirely different meaning and show the projects in an entirely different light when preceded by a concise statement of the geography, including an account of the climate; the water resources for power, irrigation, or domestic use ; the timber resources ; the geology, especially the stone available for structural purposes; the nature of the physical wealth; the biology, including the useful flora and fauna, wild or domestic; and the ethnology, especially the 
character and pursuits of the people and their availability as laborers or producers.

An inspection of the series of brochures published by the Biological Survey of the United States Department of Agriculture, and of kindred reports emanating from that department, or of the reports of the United States Geological Survey, particularly those from the geologic and hydrographic branches, or of the earlier reports of the Pacific Railroad surveys, reveals clearly the value of geographic training. Few of the writers of these reports had special geographic instruction, and, therefore, only a few had sufficient appreciation of geography in its broadest sense to enable them to systematically describe and discuss all the natural and human phenomena of the region under examination. The reports of those few who have such appreciation are in a class by themselves; they stand apart from the mediocre lists of mammals or birds, agricultural lands, or water, forest, or mineral resources. The reader obtains a clear and connected conception of all the natural features of the region and of their relation to man and his works, and is at once enabled to appreciate more definitely and comprehensively the meaning and the details of the particular work under consideration. In scarcely any other field of work, unless it be in engineering and in historical and commercial writing, is the value of a thorough geographic training more clearly evidenced. It is to the thoroughness of their geographic education throughout the whole of their school and college career that the Germans are indebted in large measure for the success of their commercial travelers and official representatives in introducing their wares among foreign peoples. These representatives know beforehand much of the resources and history of the countries to which they may be sent, and are thus able to quickly sympathize with and appreciate the peculiarities of the intabitants and to adapt themselves thereto.

From the foregoing it is evident why the more valuable and lasting reports on all of the great scientific and commercial problems of a country are rarely those written by a specialist, but those written by the man of broader geographic or administrative training; and consequently, in such undertakings, the man so taught becomes the leader and the executive, while he relegates to assistants in allied specialties, or to public institutions, the classification of the data which he has collected.

The erroneous inference should not be drawn from what has 
preceded that the writer is attempting to claim for the science of geography a superior place among the allied branches of learning. While his claim is that geography is worthy of fully as great and as distinct a place as the other sciences, he believes that it is entitled to greater prominence than any other in the school and college curriculum. It should not be taught according to the old method-the parrot-like memorizing of long lists of names of places and thingsnor yet according to the new - that form of physical or descriptive geography which has been characterized, on one hand, as geology, and, on the other, as a hash of other sciences.

The basis of geographic science or teaching is the map; hence geography is an exact and not a theoretic science. The essential in its every phase is place, and the consequent ability to visualize the place relations of objects on the face of the earth. For the broader or more advanced geographic studies the base map is necessarily but a much-generalized plan in outline. The basis from which this has been reduced is the topographic map, which Henry Gannett has aptly called the "mother-map." While the latter, because it depicts in detail all the changes in shape and slope of the surface of the earth, is the necessary base map for the study of many of the more advanced branches of geographic science, yet in consequence of its very detail it is the medium through which the first rudimentary geographic teaching can best be imparted.

Armed with a topographic map of the surrounding country, the teacher of nature studies can take the class on field excursions and, while imparting some of the rudiments of zoölogy, botany, or geology, he can at the same time indicate the relations of the various phenomena to one another and to their environment. He can point out the influence of a hill of particular outline upon a snow-drift, the run-off of water and its erosive action on the character of the soil, and the resulting growth of plants, and hence of animals. Finally, he can direct attention to the reflex influence of these upon man and his pursuits, and the places in which he has located roads and villages. The whole will open wide vistas for future indoor study, and will beget the impulse to discuss the results with geographic breadth of view and accuracy of record in written compositions.

This form of geographic instruction may well continue through several years, as the pupil advances in knowledge of elementary mathematics, astronomy, zoölogy, botany, physics, history, and drawing. $\mathrm{He}$ 
may now supplement his local field studies with the drawing of maps, which will bring into action his knowledge of exact and relative dimensions, and on these he may, as his instruction broadens from the home environment to other lands, the whole earth, and finally to the universe, indicate and discuss the relative position and influence upon each other of all natural, physical, and human phenomena.

The science of the maker of the geographic base maps, or of the cartographer, rests on a foundation of higher mathematics, including geodesy and astronomy. In like manner the science of topographic surveying is dependent on some knowledge of these and of the various branches of surveying. Hence these branches of geographic teaching should come in the more advanced college grades. The topographic map shows not only the outline plan of cultural and of water features, but also in detail the slopes, shape, and conformation of the surface of the earth. Hence it is the essential base map on which the geomorphologist, forester, agrostologist, or hydrographer records and discusses his more intricate studies. Consequently this phase of geographic teaching may wait until such time as the student shall have learned something of geology, botany, physics, and meteorology, as may the study of historical, political, or ethnologic geography wait until some instruction has been given in the sciences which bear these names.

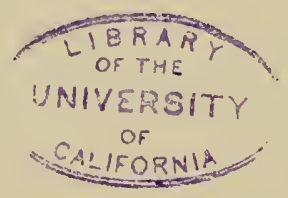







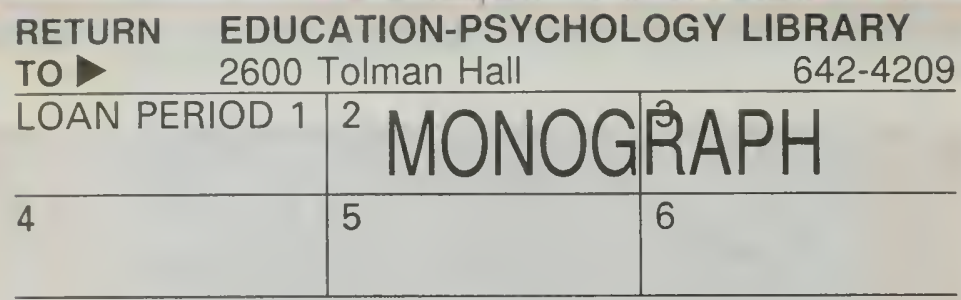

ALL BOOKS MAY BE RECALLED AFTER 7 DAYS 2-hour books must be renewed in person Return to desk from which borrowed

\section{DUE AS STAMPED BELOW}

\begin{tabular}{l|l|l}
\hline $3 / 30 / 96$ & & \\
SENT ONILL & & \\
DEC 0 1 1995 & & \\
\hline U.C. BERKELEY & & \\
\hline & & \\
\hline & & \\
\hline & & \\
\hline & & \\
\hline & & \\
\hline
\end{tabular}




\title{
U.C. BERKELEY LIBRARIES
}

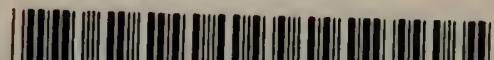 \\ C005684485
}

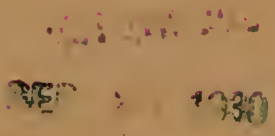




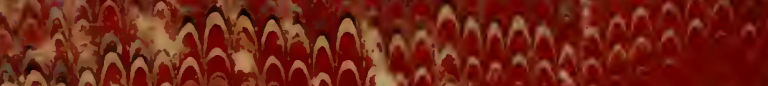

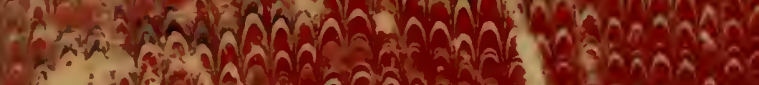

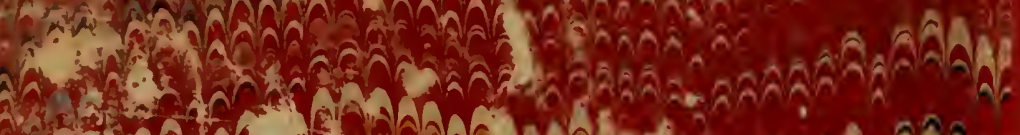

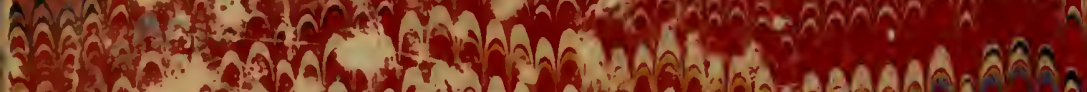
Th 3 en

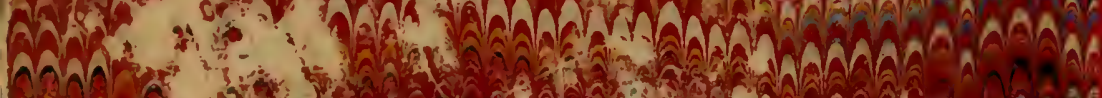

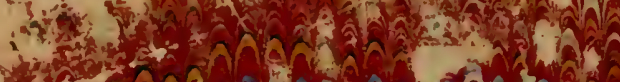

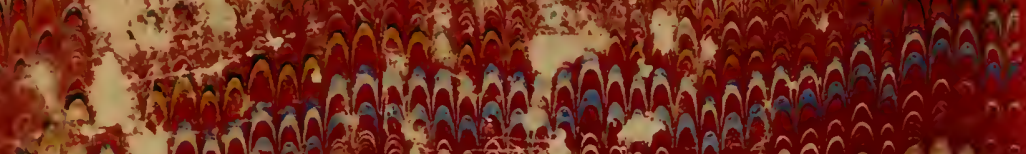

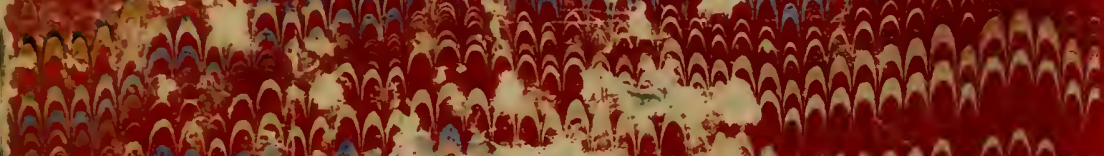

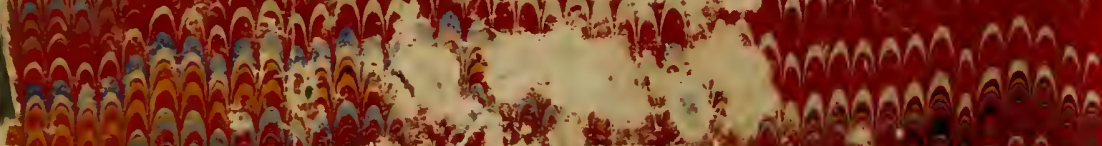

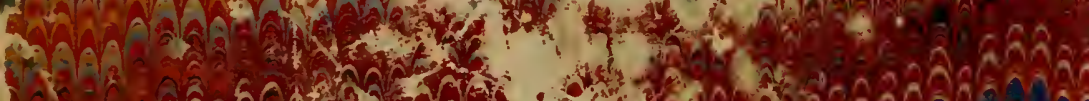

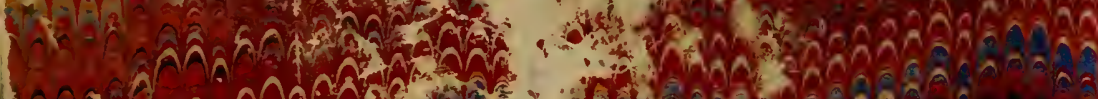

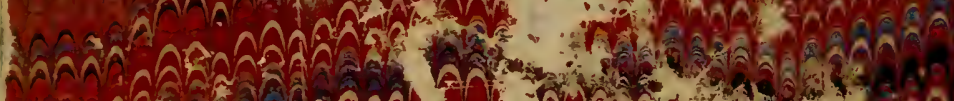

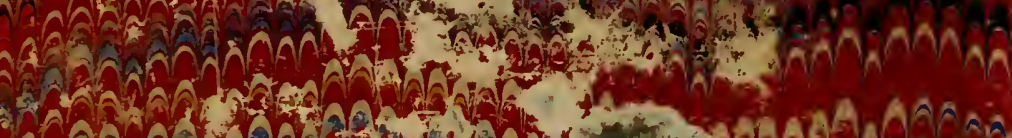

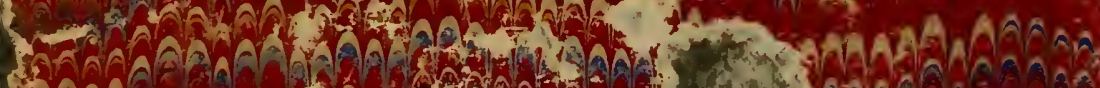

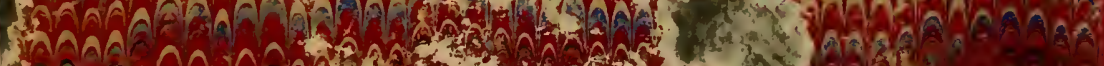

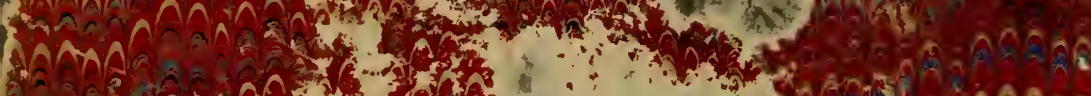

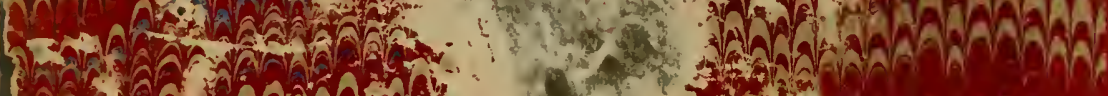
(1)

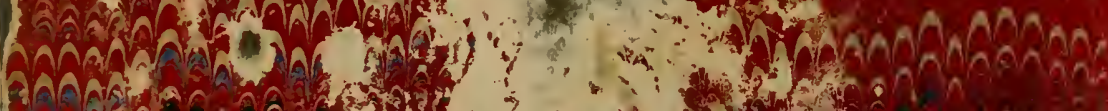

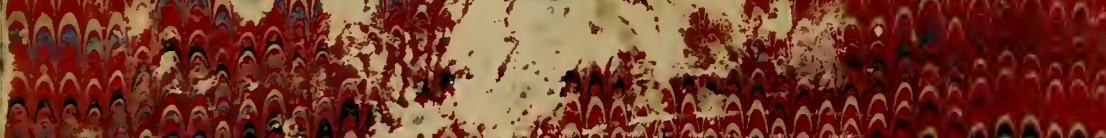

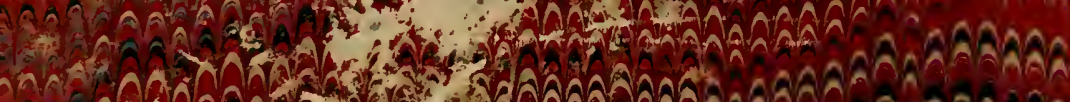

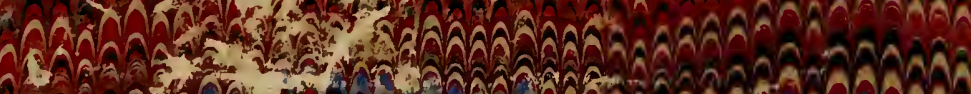

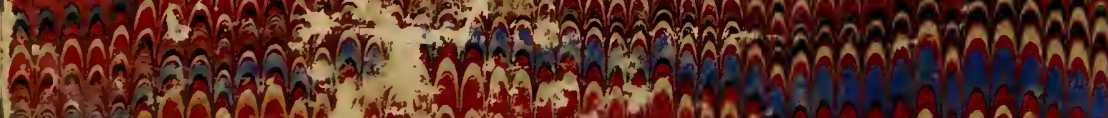

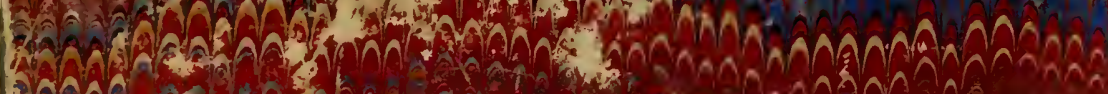
(1)

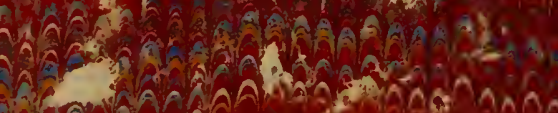

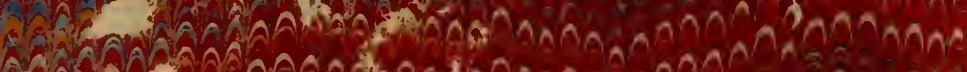
Wha

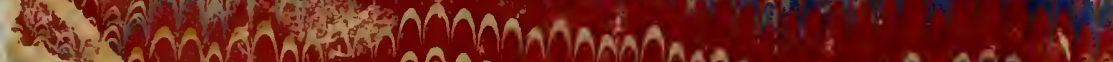
the CMA H 